3 World Health Organisation. Treatment and prevention of dehydration in diarrhoeal diseases. A guide for use at the primary level. Geneva: WHO, 1976.

4 Tallett S, MacKenzie C, Middleton P, Kerzner B, Hamilton R. Clinical, laboratory, and epidemiologic features of a viral gastroenteritis in infants and children. Pediatrics 1977; 60: 217-22.

5 Jones B J M, Brown B E, Silk D B A. Comparison of oligosaccharide and free glucose absorption from the normal human jejunum (abstract). Gut 1980; 21 : A905.

- Griffin G, Hodgson H, Chadwick V S. Restoration of fluid and electrolyte homeostasis after proximal jejunostomy: role of oral glucose polymer electrolyte therapy and water exclusion (abstract). Clin Sci Mol Med 1979; 58: 3 P.

7 Rodriguez J T, Blanco R, Gray I M. Treatment of acute diarrhoea with oral electrolyte solutions (abstract). Pediatr Res 1978; 12: 440.

8 Tripp J H, Harries J T. Letter: UNICEF/WHO glucoseelectrolyte solutions not always appropriate. Lancet 1980 ; ii: 793 .

Correspondence to Dr D B A Silk, Central Middlesex Hospital, Acton Lane, London NW10 7NS.

Received 10 September 1981

\title{
Faecal excretion of alpha-1-antitrypsin in acute diarrhoea
}

\author{
M MÄKI, A HARMOINEN, T VESIKARI, AND J K VISAKORPI \\ Department of Clinical Sciences, University of Tampere, and Department of Microbiology, \\ Tampere Central Hospital, Tampere, Finland
}

SUMMARY High levels of faecal $\alpha$-1-antitrypsin were found in children suffering from acute rotavirus diarrhoea and in children with diarrhoea in whom no microbial pathogen could be established. The results suggest that transient protein-losing enteropathy is common in acute childhood diarrhoea and may influence the outcome of the disease.

Gastrointestinal protein loss is a common phenomenon that has been demonstrated in association with more than 70 disorders affecting the gastrointestinal tract. ${ }^{1}$ There is a lack of information about protein loss during diarrhoea because methods have been cumbersome. ${ }^{1}$

Crossley and Elliott, ${ }^{2}$ and later Bernier et al. ${ }^{3}$ have shown that measurement of faecal $\alpha$-1-antitrypsin $(\alpha-1-\mathrm{AT})$ is a simple and reliable index of excessive loss of plasma proteins into the gastrointestinal tract. Recently Thomas et al. ${ }^{4}$ demonstrated its value in screening for various gastrointestinal mucosal disorders in children.

Diarrhoeal diseases are a leading cause of child death in developing countries, and the existence of a vicious circle of malnutrition and gastroenteritis is well known. ${ }^{5}$ Since rotavirus is a major pathogen of childhood diarrhoea in both temperate and tropical climates, it would be helpful to know if gastrointestinal protein loss occurs in acute rotavirus diarrhoea. We have now studied $\alpha$-1-AT content of stools from children in hospital because of diarrhoea.

\section{Materials and methods}

During a 1-year prospective study of the aetiology of childhood diarrhoea ${ }^{6}$ stool samples were randomly $\frac{1}{0}$ collected in the acute and convalescent stage of the disease for $\alpha-1-\mathrm{AT}$ measurements. The faecal samples were freshly frozen at $-20^{\circ} \mathrm{C}$.

The patients were divided according to the $\ddot{\infty}^{\circ}$ aetiology of the diarrhoea into two study groups: ? rotavirus-associated diarrhoea with no evidence 8 f other simultaneous enteropathogen (91 patients and non-specific diarrhoea with no demonstrable microbial aetiology (60 patients). In the latter group no rotavirus, adenovirus, Salmonella sp, Shigella sp.. $\mathbb{\perp}$ Yersinia sp., Campylobacter sp., diarrhoeal $\overrightarrow{\vec{P}}$ Escherichia coli or Giardia sp. could be demon- $\frac{O}{3}$ strated. For comparison the $\alpha-1-\mathrm{AT}$ content of $\bar{\sigma}$ stools was measured again in the same patients about 4 weeks after diarrhoea (60 patients, the control group).

Faecal $\alpha$-1-AT determinations were made $\frac{0}{-0}$ according to Crossley and Elliott, ${ }^{2}$ using com- 3 . mercially available immunodiffusion plates (MPartigen, Behringwerke, Marburg, W. Germany).

\section{Results}

Mean faecal $\alpha-1$-AT concentration $( \pm S E)$ in the $\frac{D}{2}$ rotavirus patients was $2 \cdot 74 \pm 0 \cdot 34 \mathrm{mg} / \mathrm{g}$ dry weight (range 0-16.88). There was no statistically significantos difference when compared with the non-specific N diarrhoea group $(3.34 \pm 0.62)$ (range $0-28 \cdot 13)$. N Both groups of patients with diarrhoea differed significantly $(P<0.001)$ from the control group $(0.44 \pm 0.06$ ) (range 0-2.80) (Fig. 1).

Faecal $\alpha$-1-AT concentration was over 1.39 $\mathrm{mg} / \mathrm{g}$ dry weight (mean of controls $+2 \mathrm{SD}$ ) in $56 \%$, $57 \%$, and $3 \%$ of the children in the respective groups. 


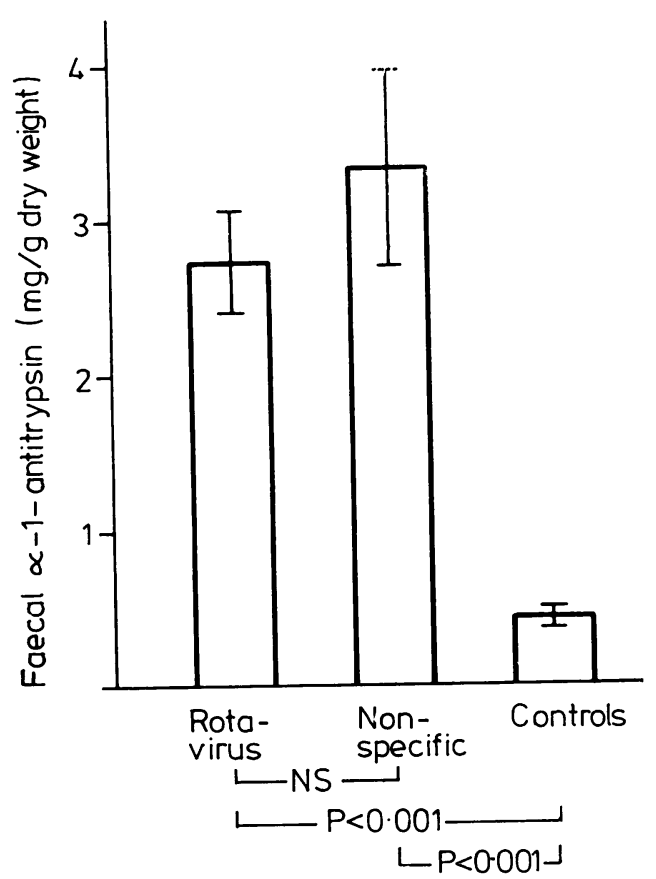

Fig. 1 Faecal $\alpha$-1-antitrypsin concentration (mean $\pm S E$ ) in children suffering from acute rotavirus $(n=91)$ and nonspecific $(n=60)$ diarrhoea and in the same children at the convalescent stage one month later (controls, $n=60$ ).

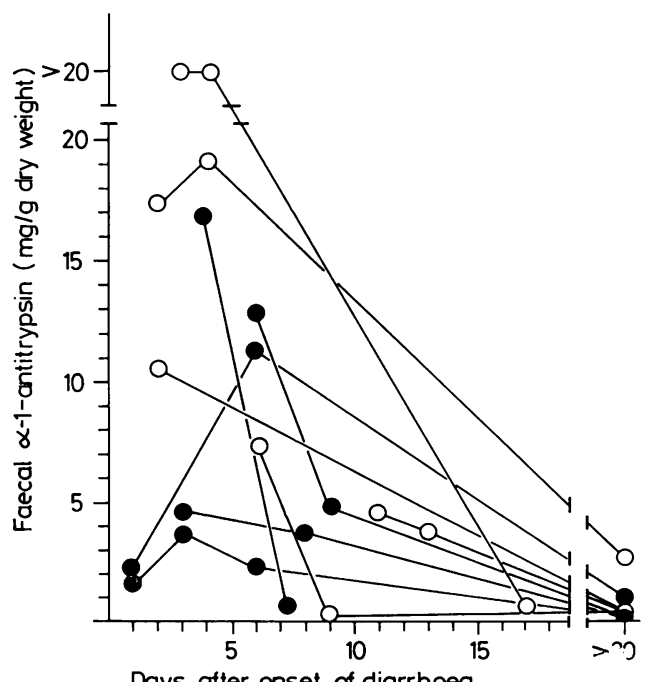

Days after onset of diarrhoea

Fig. 2 Faecal $\alpha$-1-antitrypsin concentration in serial stool specimens from 5 children with rotavirus diarrhoea (closed circles) and from 5 children with nonspecific diarrhoea (open circles).
Fig. 2 shows the faecal output of $\alpha-1-A T$ during the acute and convalescent stage of the diarrhoea in some children from whom serial stool specimens were available. Transiently high levels of $\alpha-1-\mathrm{AT}$ were seen in both study groups.

\section{Discussion}

Abnormal random faecal $\alpha$-1-AT concentrations have been found to reflect excessive serum protein loss from the gut. ${ }^{2-4}$ The test is non-invasive, non-isotopic, and is easily carried out; therefore it is suitable for children. In a recent study by Thomas et al. ${ }^{4}$ high levels of faecal $\alpha-1-\mathrm{AT}$ were found in children with coeliac disease, allergic gastroenteropathy, lymphangiectasia, nonspecific colitis, acute gastrointestinal bleeding, and active chronic inflammatory bowel disease but not from healthy children. These disorders have all previously been found to cause protein-losing enteropathy by ${ }^{51} \mathrm{Cr}$-labelled albumin excretion tests. It seems obvious that if faecal output of this protease inhibitor exceeds normal, increased permeability of plasma proteins to the gut lumen must occur because food does not contain $\alpha-1-\mathrm{AT}$.

In the present study protein-losing enteropathy was screened in about 150 children suffering from acute diarrhoea. We measured $\alpha$-1-AT from random stool specimens and freeze-dried the samples to eliminate the influence of faecal water on the results.

The findings were clear. Transiently high levels of faecal $\alpha$-1-AT were found in many children suffering from acute rotavirus diarrhoea and also in those in whom no diarrhoeal pathogen could be established. Therefore, unlike some previous observations, ${ }^{4}$ leakage of plasma proteins into the gut lumen appears a common phenomenon and one which may lead to hypoproteinaemia. ${ }^{2}$ This was not observed in our series of infants with good nutritional status. The underlying lesion leading to protein leakage during intestinal infection may vary, since similar quantities of $\alpha-1-\mathrm{AT}$ were found in rotavirus diarrhoea and in 'nonspecific' diarrhoea. In evaluating this finding one might recall that protein loss has also been shown to occur in measles enteritis. ${ }^{7}$

In conclusion, transiently high faecal $\alpha-1-\mathrm{AT}$ concentration is often found in acute childhood diarrhoea, suggesting the presence of protein-losing enteropathy. Excessive gastrointestinal protein loss may pass unnoticed in well-nourished children but may be an important trigger to the development of malnutrition in already undernourished children. These results also support the view that food intake should continue whenever possible during a diarrhoeal episode. ${ }^{8}$ 
This study was supported by a grant from the Paulo Foundation, Helsinki, Finland.

\section{References}

1 Waldmann T A. Protein-losing enteropathy. In: Card W I, Creamer B, eds. Modern trends in gastroenterology. Volume 4. London: Butterworth, 1970: 125-42.

2 Crossley J R, Elliott R B. Simple method for diagnosing protein-losing enteropathies. $\mathrm{Br} \mathrm{Med} J \mathrm{1977}$; i: 428-9.

3 Bernier J J, Florent C, Desmazures C, Aymes C, L'Hirondel C. Diagnosis of protein-losing enteropathy by gastrointestinal clearance of alpha $a_{1}$-antitrypsin. Lancet 1978 ; ii: $763-4$.

4 Thomas D W, Sinatra F R, Merritt R J. Random fecal alpha-1-antitrypsin concentration in children with gastrointestinal disease. Gastroenterology 1981; 80: 776-82.
5 Anonymous. Child mortality-nutrition-gastroenteritis-water contamination. Lancet 1978; ii : 616.

6 Vesikari T, Mäki M, Sarkkinen $\mathbf{H ~ K}$, Arstila P P Halonen $\mathbf{P}$ E. Rotavirus, adenovirus, and non-viral enteropathogens in diarrhoea. Arch Dis Child 1981; 56: 264-70.

7 Dossetor J F B, Whittle H C. Protein-losing enteropathy and malabsorption in acute measles enteritis. $\mathrm{Br} \mathrm{Med} \mathrm{J}$ 1975; ii : $592-3$.

8 Sack R B, Pierce N F, Hirschhorn N. The current status of oral therapy in the treatment of acute diarrheal illness. Am J Clin Nutr 1978; 31 : 2252-7.

Correspondence to Dr M Mäki, Department of Clinical Sciences, University of Tampere, PO Box 607, SF-33101 Tampere 10, Finland.

Received 6 October 1981

\title{
Haemoglobin levels and blood requirement in thalassaemia
}

\author{
V GABUTTI, A PIGA, P NICOLA, C VUllo, L CAPRA, A DI PALMA, G MASERA, \\ $S$ TERZOLI, AND R MAURI
}

Clinica Pediatrica, Università di Torino, Divisione di Pediatria, Arcispedale S Anna, Ferrara

Cattedra di Puericultura, Università di Milano

SUMMARY The relationship between blood requirement and the mean level of maintained haemoglobin was examined in 392 patients with homozygous $\beta$-thalassaemia. Pre- and post-transfusional haemoglobin levels and the amounts of blood transfused were measured during a 1-year period. No significant differences were noted in the blood requirements of patients (splenectomised or not) irrespective of the haemoglobin level. It may be supposed that if the mean haemoglobin level is high the haematopoietic activity is inhibited, and hence the bone marrow mass and total blood volume are reduced. High haemoglobin levels may thus be obtained with no increase in blood intake.

An understanding of the relationship between the amount of blood transfused and the mean haemoglobin $(\mathrm{Hb})$ level maintained in patients with homozygous $\beta$-thalassaemia is important when assessing the risks and benefits of transfusion; it is important, too, in the clinical management of the patient. Data are scanty and conflicting. Modell ${ }^{1}$ reported a linear correlation between these two measurements, but Propper et al. ${ }^{2}$ found that the $\mathrm{Hb}$ level could be raised without increasing the amount of blood transfused, except during the initial few months. It was decided therefore to examine this question on a larger scale, using patients collected from three centres.

\section{Material and methods}

A total of 392 subjects aged between 2 and 23 years (166 from Turin, 158 from Ferrara, and 68 from Milan) were studied for 2 years. One hundred and eighty-four of them had been splenectomised. Any patient with hypersplenism or signs of isoimmunisation, or any patient who underwent splenectomy during the period of observation was excluded. Patients were transfused as outpatients every 25-30 days with one or two blood units. The amount that $\mathrm{Hb}$ levels increased by transfusion was $3 \cdot 5-4 \mathrm{~g} / \mathrm{dl}$. The mean $\mathrm{Hb}$ level maintained was calculated as the average of the pre- and posttransfusional values during one year. ${ }^{1}$ The blood consumption was determined as the amount of blood ( $\mathrm{ml}$ of concentrated red cells with haematocrit $(75-85 \%)$ ) transfused during the same period, divided by the body weight in June.

$\mathrm{The} \mathrm{Hb}$ levels were classified into groups so that the mean blood consumption could be statistically analysed by means of Student's $t$ test; the paired-data $t$ test was used to compare the requirement in each year of any patient in whom the $\mathrm{Hb}$ level increased. 